\title{
Modeling Customer Bounded Rationality in Operations Management: A Review and Research Opportunities
}

\author{
Hang Ren ${ }^{\mathrm{a}}$, Tingliang Huang ${ }^{\mathrm{b}, *}$ \\ ${ }^{a}$ UCL School of Management, Level 38 One Canada Square, Canary Wharf, London, E14 \\ $5 A A$, United Kingdom \\ ${ }^{b}$ Carroll School of Management, Boston College, 140 Commonwealth Avenue, Chestnut \\ Hill, MA 02467, United States
}

\begin{abstract}
Many studies in operations management started to explicitly model customer behavior. However, it is typically assumed that customers are fully rational decision-makers and maximize their utility perfectly. Recently, modeling customer bounded rationality has been gaining increasing attention and interest. This paper summarizes various approaches of modeling customer bounded rationality, surveys how they are applied to relevant operations management settings, and presents the new insights obtained. We also suggest future research opportunities in this important area.

Keywords: Bounded rationality, behavioral operations, customer behavior, operations management
\end{abstract}

\section{Introduction}

How to model "demand" plays an important role in the operations management (OM) literature. Historically, an exogenous (and aggregate) demand distribution is assumed. Later, it is recognized in the OM research community 5 that demand depends on how customers react to firm strategies. Therefore, customer-driven demand models emerge. Customers are assumed not to anticipate future prices or availability; they are myopic and purchase if their current

\footnotetext{
* Corresponding author

Email address: tingliang.huang@bc.edu (Tingliang Huang)

Preprint submitted to Computers \& Operations Research
}

October 13, 2017 
utility from purchasing is positive. The recent body of literature started to investigate forward-looking or strategic customers who strategically time their purchases in anticipation of future discounts. A key common assumption made in this extensive literature is that customers are fully rational: they are perfect utility-maximizers and form "rational expectations" about the firm's strategies; that is, they perfectly anticipate the firm's strategies in equilibrium. Undoubtedly, this is a strong assumption in some real settings. Then a natural and important question for both academics and practitioners is how robust the existing findings and managerial insights are with respect to this "full rationality" assumption.

The concept of bounded rationality was introduced into OM from the economics literature. Simon [1, 2] coins the term "bounded rationality" to refer to decision-making behaviors where the agent searches over alternatives and settles on a "satisfactory" (not necessarily the optimal) solution. Later, economics researchers have constructed a variety of modeling frameworks to capture agents' bounded rationality, e.g., the quantal response model [3, 4, 5], the anecdotal reasoning framework [6, 7], and the cognitive hierarchy model [8, 9].

The remainder of this paper is as follows. In Section 2, we present bounded rationality frameworks in the economics literature that are relevant for OM. Next, we review the literature of modeling customer bounded rationality in Section 3 in OM settings, especially service operations management (SOM) and revenue management (RM). We conclude the survey in Section 4 and discuss future research opportunities.

\section{Approaches to Model Bounded Rationality}

In this section, we review several approaches to model bounded rationality that are relevant for OM settings. We focus on the psychological underpinnings and economics theories of these approaches, and will discuss their OM applications in the next section. For brevity, this review does not provide an exhaustive list of all approaches to model bounded rationality and we refer interested read- 
ers to [6, 7] for comprehensive reviews of bounded-rationality models in the economics literature.

\subsection{Logit Choice Model}

It is well-established in the psychology literature that human decision-makers are not consistent in their comparative judgment in the sense that they give different judgements about the same pair of stimuli from one occasion to the next [10]. This observation is illustrated vividly by the famous Weber's Law, which states that the just-noticeable difference between two stimuli is proportional to

45 their magnitude [11. As a result of the judgment inconsistency, the human decision-maker's choice behavior is usually probabilistic [3], choosing each candidate with positive probability. In addition, according to the Fechner's Law [12, the subjective sensation is proportional to the logarithm of the stimulus intensity. Therefore, Thurstone [10, 13] concludes that the more intense stimulus is chosen more often, which he formalizes as the Law of Comparative Judgment. Based on Thurstone's work, Luce [3] axiomatizes the choice behavior and shows that better choices (in the sense of higher v-scale, see Theorem 3 on p. 23 of [3]) are chosen more often.

To motivate this choice model, consider an example in which a decisionmaker chooses between an action that entails payoff $v>0$, and an outside option that entails null payoff. Obviously, a fully rational decision-maker takes the action for sure. Now suppose that she is boundedly rational in the sense of estimating the payoff of taking the action as $v+\epsilon$, where $\epsilon$ represents an zeromean random estimation error. We focus on the logit choice model by assuming that $\epsilon$ follows a logistic distribution $F(x)=1 /\left(1+e^{-x / \theta}\right)$, where $\theta>0$ captures the error term's standard deviation $\sigma(\sigma=\pi \theta / \sqrt{3})$. This assumption is a result of the axiom of Independence of Irrelevant Alternatives [3], and it has been adopted extensively in the economics and OM literature. In addition, we assume that the decision-maker accurately estimates the payoff of the outside option. Therefore, the boundedly rational decision-maker takes the action when 
$v+\epsilon \geqslant 0$ and the outside option otherwise, i.e., the probability to act is

$$
P(\epsilon \geqslant-v)=1-F(-v)=\frac{e^{v / \theta}}{1+e^{v / \theta}} .
$$

Note that $\theta$ captures the decision-maker's level of bounded rationality. In particular, as $\theta$ goes to zero, the random error vanishes and she takes the action for sure. Conversely, as $\theta$ goes to infinity, the error is so noisy that the action payoff $v$ is fully overshadowed and the decision-maker takes the action and the outside option with equal probability.

To interpret the choice model in another way, we denote $p \equiv P(\epsilon \geqslant-v)$ and rewrite Equation (1) as

$$
\ln \left(\frac{p}{1-p}\right)=\frac{v}{\theta},
$$

where the left-hand side (LHS) is the log odd of taking the action. Therefore, the logit choice model can be explained as decision-making following the classic logit regression model. Equation (2) also shows that $\theta$ represents the level of bounded rationality by measuring how sensitive the payoff of action influences the decision: a more boundedly rational decision-maker (i.e., higher $\theta$ ) is less responsive to an increase in the payoff of taking the action.

The above logit choice model can be easily generalized to include more actions. Suppose that the decision-maker has $K$ actions, each one leading to payoff $u_{k}(k \in\{1, \ldots, K\})$. In the logit choice model, her probability of choosing action $k$ is

$$
p_{k}=\frac{e^{u_{k} / \theta}}{\sum_{l=1}^{K} e^{u_{l} / \theta}} .
$$

The model can be further extended to continuous choices. Suppose that the decision-maker chooses an action $x \in S$ and her payoff of choosing $x$ is $u(x)$. In the logit choice model, her choice is a probability distribution on support $S$ with the density function

$$
f(x)=\frac{e^{u(x) / \theta}}{\int_{S} e^{u(t) / \theta} d t} .
$$

65 A more systematic treatment of the logit choice model is available from [3, 14, 15. 
Based on the logit choice model, McKelvey and Palfrey [4] and Chen et al. [5] develop the concept of the logit quantal response equilibrium (QRE), in which each player follows the logit choice model and believes that other players do so as well. To formalize this idea, consider a normal-form game with a set of $N=\{1, \ldots, n\}$ players. Each player $i \in N$ has a strategy set $S_{i}=$ $\left\{s_{i}^{1}, \ldots, s_{i}^{k_{i}}\right\}$ consisting of $k_{i}$ pure strategies, and a von Neumann-Morgenstern (vNM) utility function $u_{i}: S \rightarrow \mathbb{R}$, where $S=\prod_{i \in N} S_{i}$ denotes the set of all players' pure strategy combinations. Moreover, we denote by $\Delta_{i}\left(S_{i}\right)$ the set 75 of probability distributions on $S_{i}$ and refer to $\pi_{i} \equiv\left\{\pi_{i}^{1}, \ldots, \pi_{i}^{k_{i}}\right\} \in \Delta_{i}\left(S_{i}\right)$ as a mixed strategy of player $i$, where $\pi_{i}^{j}$ is her probability of choosing action $j$. In addition, denote $\pi_{-i}$ as the strategy profile of all players except player $i$, i.e., $\pi_{-i} \equiv\left\{\pi_{1}, \ldots, \pi_{i-1}, \pi_{i+1}, \ldots, \pi_{n}\right\} \quad\left(\pi_{j} \in \Delta_{j}\left(S_{j}\right)\right.$ for all $\left.j \in N\right)$. Consistent with the definition of the logit choice model, we define a player's logistic choice response as below.

Definition 1. Given player $i$ 's belief about other players' mixed strategy profile $b_{-i} \equiv\left\{b_{1}, \ldots, b_{i-1}, b_{i+1}, \ldots, b_{n}\right\} \quad\left(b_{j} \in \Delta_{j}\left(S_{j}\right)\right.$ for all $\left.j \in N\right)$, her mixed strategy $\sigma_{i}\left(b_{-i}\right) \in \Delta\left(S_{i}\right)$ is a logistic response to $b_{-i}$ with precision $\theta$ if for all $k \in$ $\left\{1, \ldots, k_{i}\right\}$,

$$
\sigma_{i}^{k}\left(b_{-i}\right)=\frac{e^{u_{i}\left(s_{i}^{k}, b_{-i}\right) / \theta}}{\sum_{l=1}^{k_{i}} e^{u_{i}\left(s_{i}^{l}, b_{-i}\right) / \theta}} .
$$

The logit QRE is defined by an equilibrium where each player responds logistically to other players' strategy profile, which is also a combination of logistical responses. The formal definition is given as below.

Definition 2. A mixed strategy profile $\pi=\left(\pi_{1}, \ldots, \pi_{n}\right) \in \prod_{i \in N} \Delta\left(S_{i}\right)$ is a logit QRE if for all pure strategy $s_{i}^{l} \in S_{i}$ of each player $i$,

$$
\pi_{i}^{s_{i}^{l}}=\sigma_{i}^{s_{i}^{l}}\left(\pi_{-i}\right) .
$$

We refer interested readers to [4 for the proof of the existence of a logit 85 QRE in any normal-form game. Moreover, Definition 2 can be generalized to incorporate heterogeneous levels of bounded rationality across players 4]. The 
logit QRE has been extensively applied in the economics literature, including auction [16, 17, bargaining [18, and monopolistic screening [19].

\subsection{Anecdotal Reasoning}

The standard decision theory assumes that the decision-maker fully understands the situation and makes decisions based on it rationally. However, this requirement may not hold in practice. For example, a customer may not know the average food quality in a restaurant because she patronizes it infrequently. A patient may not be able to estimate the healthcare quality of a particular provider due to a lack of relevant expertise.

These assumptions become even more demanding in a game-theoretical setting. As Osborne and Rubinstein 20 point out, the concept of Nash equilibrium requires each player to not only know her own set of actions and payoffs, but also form correct beliefs about the various uncertainties she faces (e.g., the number of other players and their payoffs). Even if the player has full information, she may still not make decisions fully rationally because it is usually challenging to recognize the connection between the actions of the decision-maker and her opponents with an outcome of the game in real-time decision makings.

Although the decision-maker may not fully understand the situation, she can usually connect each action to several independent outcomes from anecdotal evidence. For example, the customer may know the food quality experienced by acquaintances who have been to the restaurant before, and the patient may hear complaints and/or compliments about the healthcare quality of a hospital from other patients. To capture decision-making based on anecdotes, Osborne and Rubinstein [20] proposed the anecdotal reasoning framework [20, where the decision-maker takes the average payoff across all anecdotes related to each action, and then chooses the action with the highest average payoff. In other words, she makes decisions as if her payoff from each action is equal to the average payoff from anecdotes. This is consistent with the representativeness heuristic in the psychology literature [21, 22, in which people expect a small sample to mirror the probability distribution from which it is drawn. 
To illustrate this decision rule, consider an example where a decision-maker chooses between an action that leads to a random payoff $\mathcal{V}$, and an outside option that entails null payoff to maximize the expected payoff. $\mathcal{V}$ is normally distributed with mean $V>0$ and standard deviation $\sigma$, i.e., $\mathcal{V} \sim N\left(V, \sigma^{2}\right)$. Obviously, a rational decision-maker takes the action for sure. With anecdotal reasoning, she samples the action $k$ times to obtain i.i.d. payoff samples $\mathcal{V}_{i}(i \in\{1, \ldots, k\})$, and then chooses to take the action if $\frac{\sum \mathcal{V}_{i}}{k} \geqslant 0$. Since $\frac{\sum \mathcal{V}_{i}}{k} \sim N\left(V, \sigma^{2} / k\right)$ by $\mathcal{V}_{i} \sim N\left(V, \sigma^{2}\right)$, the decision-maker takes the action with probability

$$
P\left(\frac{\sum \mathcal{V}_{i}}{k} \geqslant 0\right)=1-\Phi(-V \sqrt{k} / \sigma),
$$

where $\Phi(\cdot)$ denotes the cumulative distribution function of the standard normal distribution. This choice behavior suggests that the decision-maker errs by taking the action less than a fully rational counterpart. Moreover, $k$ measures the decision-maker's rationality level: as $k$ goes to infinity, the average payoff across anecdotes reflects $V$ accurately, so the decision-maker takes the action for sure. Also note that the uncertainty of $\mathcal{V}$ is indispensable. Otherwise, anecdotal reasoning leads to no bounded rationality because each anecdote accurately reflects the true payoff of action.

125 The example above illustrates anecdotal reasoning when there is only one decision-maker. To characterize the choices of multiply players, all of whom use anecdotal reasoning, Osborne and Rubinstein [20] propose the $S(k)$-equilibrium. In this equilibrium, all players use mixed strategies, and the probability for a player to choose a particular action is equal to the probability that this action leads to the highest average payoff across $k$ anecdotes. Next, we provide the formal definition of the $S(k)$ symmetric equilibrium in a normal-form two-player game 20 .

Consider a symmetric normal-form game with two players. Each player has a strategy set $S=\left\{s_{1}, \ldots, s_{m}\right\}$ consisting of $m$ pure strategies, and a vNM utility 135 function $u: S \times S \rightarrow \mathbb{R}$. Moreover, we denote by $\Delta(S)$ the set of probability distributions on $S$ and refer to $\sigma \in \Delta(S)$ as a mixed strategy. For each strategy 
$s_{i} \in S$, let $\mathscr{V}\left(s_{i}, \sigma, k\right)$ be the random variable equal to the average of $k$ independent random variables, each of which yields $u\left(s_{i}, s_{j}\right)$ with probability $\sigma\left(s_{j}\right)$ for each $s_{j} \in S$. Therefore $\mathscr{V}\left(s_{i}, \sigma, k\right)$ represents a player's average payoff from $k$ anecdotes in which the other player follows the mixed strategy $\sigma$. Denote by $w\left(s_{i}, \sigma, k\right)$ the probability that the strategy $s_{i}$ obtains the highest average payoff, i.e., $w\left(s_{i}, \sigma, k\right)=P\left(\mathscr{V}\left(s_{i}, \sigma, k\right)>\mathscr{V}(x, \sigma, k)\right)$ for all $x \in S$. Moreover, ties are broken by an equiprobability rule.

Definition 3. For any positive integer $k$, an $S(k)$-equilibrium is a mixed strategy $\sigma$ that satisfies

$$
w\left(s_{i}, \sigma, k\right)=\sigma\left(s_{i}\right)
$$

for every strategy $s_{i} \in S$.

It is straightforward to generalize the above definition to include more than two players and incorporate the asymmetric game (see Definition 2 of [20]). In addition, Osborne and Rubinstein [20] show the existence of a $S(k)$-equilibrium and its convergence to a mixed-strategy Nash equilibrium (NE) when $k \rightarrow \infty$.

Over the past decade, economists have applied the $S(k)$-equilibrium to model customers' anecdotal reasoning. Spiegler [23] studies a price-competition game of $n$ "quacks," whose treatment does not influence the patient's probability of recovery. This market is inactive when patients are fully rational. When they use anecdotal reasoning, however, the market becomes active and patients suffer from a welfare loss due to bounded rationality. Szech [24] endogenizes the quacks' service quality decision and shows that they mainly offer mediocre qualities in all subgame-perfect Nash equilibria (SPNE). Spiegler [25] considers another price-competition game where the customer uses anecdotal reasoning in estimating the prices of all firms. Because of bounded rationality, increased competition may not lead to more competitive pricing, which harms customers' welfare. 


\subsection{Cognitive Hierarchy}

The concept of Nash equilibrium requires the common knowledge of rationality, i.e., each player makes rational choices, knows that other players make rational choices, and knows that other players know that she makes rational do not exhibit this common rationality. As an example, consider the well-known Keynesian beauty contest game where players are asked to pick numbers from 0 to 100 , and the player whose number is closest to $2 / 3$ of the average wins a prize. If there is a tie, the prize is divided equally among the winners. It can contrast, experiments by Nagel [9] and Camerer et al. 27] show that the group average is typically between 20 and 35. To quote Camerer et al. 27, "some players are not able to reason their way to equilibrium value, or they assume that others are unlikely so."

To model decision-makings in these experiments, Stahl and Wilson 8 and Nagel 9] propose the cognitive hierarchy model (also referred to as the level$k$ model), where players are categorized into $k$ levels based on their reasoning sophistication. Level-0 players choose a random [8] or naive [9] strategy, e.g., picking 50 in the beauty contest game. Then level- $k$ players choose the best response assuming that all other players are level-0, level-1, .., level- $(k-1)$ players. In the commonly-used Poisson cognitive hierarchy model, the frequency of the level- $k(k \in\{0,1, . .,+\infty\})$ players $f_{k}$ follows a Poisson distribution:

$$
f_{k}=\frac{e^{-\tau} \tau^{k}}{k !} .
$$
$\tau$ measures the average level of sophistication of the population: as $\tau \rightarrow+\infty$, the prediction of the Poisson cognitive hierarchy model converges to a Nash equilibrium. We refer interested readers to [27] for a formal definition and some theoretical properties of the Poisson cognitive hierarchy model. The cognitive hierarchy model has been widely applied in the economics and marketing liter- 
diffusion [30, market entry competition [31, market platform competition [32], and moviegoer behaviors 33 .

\subsection{Hyperbolic Discounting}

It has been well-documented (see e.g., 34, 35, 36, 37, 38, ) that delaying a

consumption to a future time discounts its net present value for the customer. To model this time preference, Paul Samuelson [39] proposes exponential discounting, in which the discount function (i.e., the weight on rewards received at time $t$ ) is $D(t)=e^{-r t}$. Exponential discounting captures the time-preference of a rational decision-maker, because the discount function implies that customer's inter-temporal preferences are dynamically consistent, i.e., the rate of discounting is independent of the time of consumption. To see this with mathematical precision, consider a consumption that leads to immediate utility $u$. If the customer defers her consumption from time $t$ to $t+\Delta t$, then the utility is discounted by $e^{-r(t+\Delta t)} / e^{-r t}=e^{-r \Delta t}$, which does not depend on $t$.

However, experiments have revealed that exponential discounting does not match human decision-makers' actual time preference whose rate of discounting is declining in time [40, 41, 42, 43, 44, 45]. For example, Richard Thaler [40] find that in a particular experiment setting, the subjects exhibit an average discount rate of 345 percent over a one-month horizon, 120 percent over a oneyear horizon, and 19 percent over a ten-year horizon. We refer interested readers to Frederick et al. [46] for an extensive review of the empirical studies.

To capture the declining rate of discount observed in experiments, researchers have proposed the following types of discount function: $D(t)=1 / t$ by Ainslie [47, $D(t)=1 /(1+\alpha t)$ by Herrnstein [48] and Mazur [49], and $D(t)=1 /(1+$ $\alpha t)^{r / \alpha}$ by Loewenstein and Prelec [50]. Discounting using the above functions are referred to as hyperbolic discounting because all the discount functions are in the generalized hyperbolic form. In addition, Laibson [51] proposes the quasihyperbolic discounting to introduce hyperbolic discounting in the discreet-time setting while maintaining the analytical tractability similar to exponential discounting. In this framework, rewards in the current time period are undis- 
counted, and rewards occurring $t$ periods in the future are discounted by $\beta \delta^{t}$, where $\beta, \delta \in(0,1)$. Hyperbolic and quasi-hyperbolic discounting have been applied in economics models to study the consumption-savings decisions [51, addiction [52], and health club memberships [53].

\subsection{Reference Dependence and Loss Aversion}

The classic economics theory assumes that decision-makers maximize the expected utility. However, there is significant empirical evidence (see, e.g., 54, 55. 56]) which suggests that people perceive outcomes not in terms of their absolute utilities, but as gains and losses relative to a reference point, i.e., their preferences exhibit reference dependence. Moreover, they exhibit loss aversion in the sense of being more sensitive to a utility loss than a utility gain of the same amount [54]. Heidhues and Koszegi [57, 58, 59] and Koszegi and Rabin [60] incorporate customers' reference dependence in economics models by modifying their utility function into

$$
u(c \mid r)=m(c)+n(c \mid r),
$$

where $c$ denotes the consumption bundle and $r$ the reference point. Equation (4) shows that the loss-averse decision-maker's utility consists of two parts: the "outcome-based utility" $m(c)$ classically studied in economics, and the "gain-loss utility" $n(c \mid r)$ that captures the utility gains and losses relative to the reference 220 point.

As a concrete example of Equation (4), consider the classic newsvendor problem with production cost $c$, selling price $p$, and salvage value $s$. In addition, assume that the newsvendor uses the demand realization $d$ as the reference point and incurs a psychological cost $\delta_{o}$ per leftover inventory and $\delta_{u}$ per unfulfilled order. $\delta_{o}>\delta_{u}$ by loss aversion. According to Equation (4), the newsvendor's utility by ordering $x$ is

$$
p \min \{x, d\}+s(x-d)^{+}-c x-\delta_{o}(x-d)^{+}-\delta_{u}(d-x)^{+},
$$

where $(t)^{+} \equiv \max \{t, 0\}$. Note that $p \min \{x, d\}+s(x-d)^{+}-c x$ is the outcomebased utility and $-\delta_{o}(x-d)^{+}-\delta_{u}(d-x)^{+}$is the gain-loss utility. 
Loss aversion has been extensively applied in the economics and marketing literature to study the endowment effect [56], downward-sloping labor supply 61, the disposition effect 62, 63, 64, the equity premium puzzle 65, asymmetric price elasticities [66, 67, and insensitivity to bad income news [68, 69.

\section{Bounded Rationality in Operations Management}

Classic OM models usually impose strong assumptions on customers' decisionmakings. For example, the traditional SOM literature assumes that customers can perfectly evaluate the benefits and costs of joining a queue. However, they usually lack this full rationality in practice because of scarce information and their inability to accurately estimate expected waiting time. Moreover, the RM literature typically assumes that customers aim to maximize their long-run utility from visiting a firm periodically, whereas they may actually make purchase decisions anchoring on a reference price.

In this section, we review the literature that incorporates customer bounded rationality in OM settings. We will focus on SOM and RM, and include only a few papers in the supply chain management (SCM) literature. This is due to two considerations. First, the existing SCM literature concerns mainly about bounded rationality born by a firm (e.g., a newsvendor) instead of customers. Second, 70. has already provided an excellent review on bounded rationality in SCM. Moreover, we will organize the literature by the type of customer bounded rationality in the same order as Section 2. To highlight the contributions and limitations of incorporating customer bounded rationality in each OM setting, we have also summarized the literature in Table 1 


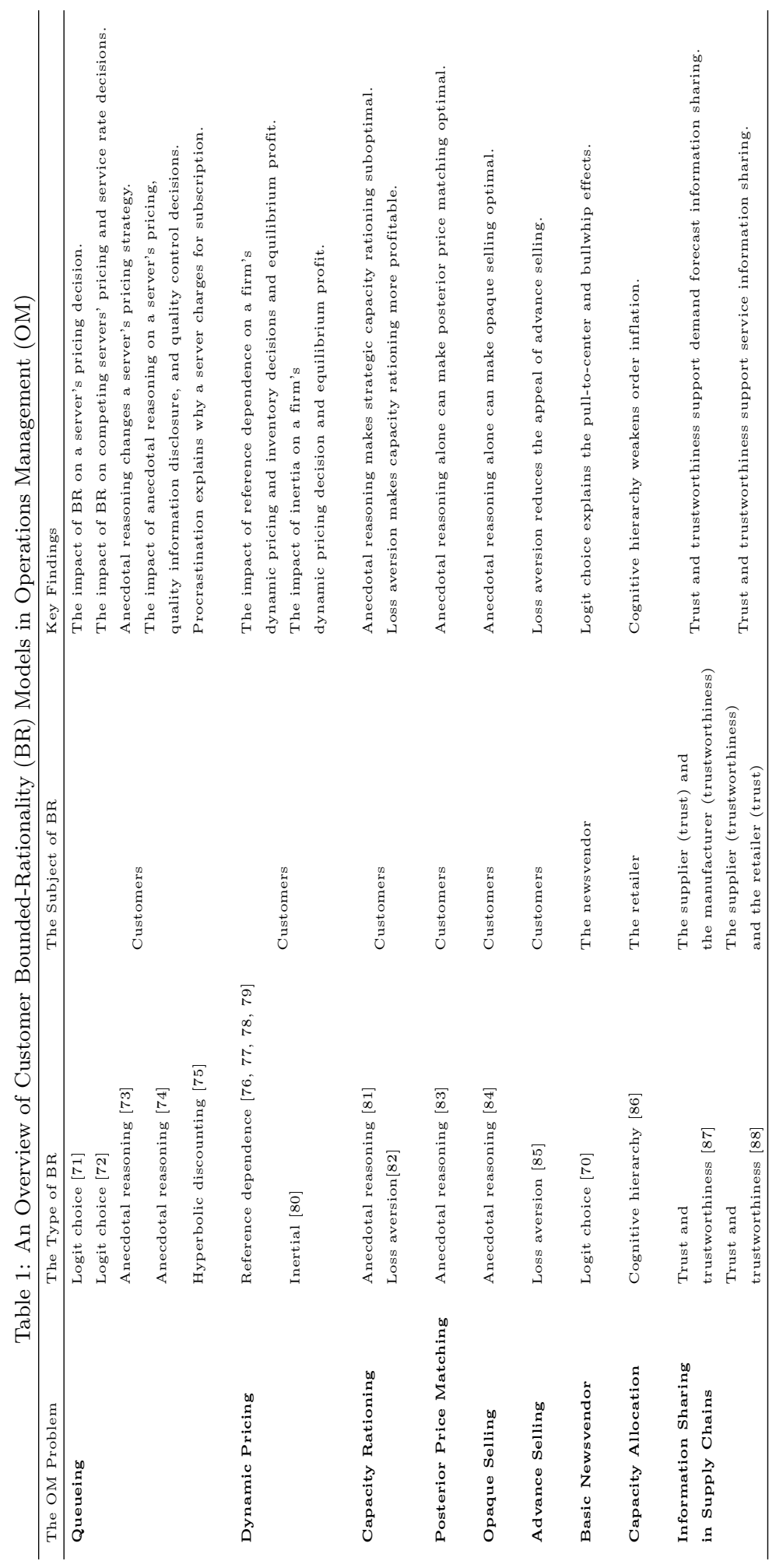




\subsection{Logit Choice Model}

The classic SOM literature assumes that customers are able to form rational expectations about all queueing system parameters when making their join-orbalk decisions (see [89] for an extensive review). In practice, however, it may 
ing the servers' pricing decisions, $\mathrm{Li}$ et al. find that when the service is sufficiently customer-intensive, customer bounded rationality increases (decreases) the servers' expected revenue under high (low) arrival rate.

Apart from SOM, the logit choice model has also been applied by $\mathrm{Su}[70$ in SCM to study the implications of a newsvendor's bounded rationality. Specifically, $\mathrm{Su}$ considers a newsvendor who may order any quantity between the smallest and the largest possible demand realizations. Moreover, the probability density of each ordering quantity $f(x)$ depends on the corresponding payoff $u(x)$, as given by Equation (3). Assuming that the demand is uniformly distributed, Su shows that the expected ordering quantity is higher (lower) than the critical fractile solution when the solution is lower (higher) than the average demand. In other words, a newsvendor's bounded rationality in the form of logit choices can induce the pull-to-center effect. We provide our explanation as follows. When the critical fractile solution is high, the logit choice newsvendor is more prone to under-ordering than over-ordering because there are more reasonable ordering quantities (which leads to non-negative profits) below the optimal one than those above it. Since the newsvendor chooses all these ordering quantities with positive probability, the average ordering quantity is lower than the optimal one. Then Su applies the logit choice newsvendor model to show that bounded rationality alone can support the bullwhip effect: upstream decision-makers order with greater variability to correct for the mistakes that the newsvendor may make.

\subsection{Anecdotal Reasoning}

Although the logit choice model allows for customer bounded rationality in terms of their computational limitations, it still imposes a strong assumption on their understanding of the system. For example, Huang et al. 71 and Li et al. 72] assume that customers know all service system parameters, e.g., the arrival process, the service rate, and the service quality. In practice, however, they may lack such knowledge and rely on earlier customers' service experiences (i.e., anecdotes) to estimate the parameters [90. Due to the intrinsic uncertainties 
underlying customers' arrival process and the firm's service provision, these anecdotes may not accurately represent the situation customers will face, i.e., they are boundedly rational.

Huang and Chen 73 incorporate customer anecdotal reasoning in estimating the expected waiting time of a service system. Instead of forming an accurate estimate based on the knowledge of the arrival process and the service rate, customers rely on the waiting time anecdotes from earlier customers to infer their own waiting time. Huang and Chen characterize customers' equilibrium joining behavior and the service provider's pricing decision under revenue and welfare maximizations. They find that a revenue-maximizing service provider may raise price as the arrival rate increases. If the service provider can adjust capacity, her optimal price may decrease in the arrival rate. Both results go against the pricing recommendations in the fully rational benchmark.

In another paper, Ren et al. 74 investigate the managerial implications of customer anecdotal reasoning in estimating service quality. Specifically, they consider an $\mathrm{M} / \mathrm{M} / 1$ queue in which the service quality is intrinsically uncertain and customers do not know its distribution. To estimate the service quality, a customer acquires several anecdotes from earlier customers, and then takes the sample average as the service quality she will receive. Ren et al. show that anecdotal reasoning generates customer bounded rationality by heterogenizing ex ante homogenous customers, i.e., they overestimate/underestimate service quality if the samples happen to be good/bad. They Ren et al. examine the impact of customer anecdotal reasoning on a service provider's pricing, service quality, and quality information disclosure decisions. They find that a lowquality service provider prices higher than the fully rational benchmark, whereas a high-quality provider prices lower. When the service provider also has control over quality, a larger size of anecdotes may lead her to reduce quality instead of improving it. Moreover, a high-quality service provider may not disclose 335 information if the sample size is small, whereas a low-quality service provider may disclose if the sample size is large.

Customer anecdotal reasoning may also play an important role in RM, in 
which their purchase decisions rely on the anticipation of uncertainties about product quality, price, and availability. A fully rational anticipation is usually challenging for customers due to scarce information. Therefore, they may resort to anecdotal reasoning as a simplified heuristic. For example, in deciding to buy a product now or later, a customer needs to form an expectation about the product availability in the future. The traditional literature on customers' strategic behavior (see [91] for an extensive review) assumes that they can form rational expectations. This assumption can be justified in settings where customers have frequent and repeated interactions with a firm (e.g., grocery and apparel stores). In the setting of buying durable products, however, customers usually have scarce opportunities to learn a firm's stockout probability. Therefore, they may estimate it based on anecdotes.

Huang and Liu [81] incorporate this anecdotal reasoning into customers' decision-makings and study its impact on a firm's strategic rationing decision. In line with the traditional dynamic pricing literature, Huang and Liu consider a monopolistic firm selling a single type of product across two periods at exogenous prices, with the period-1 price higher than the period-2 price. Customers are heterogeneous in their product valuations and a portion of them arrive at the firm in period 1, who decide to buy or wait for period 2. The other customers arrive in period 2 and decide to buy or not. The customers do not know the probability of stockout in period 2 and they assume that it is equal to the number of stockout instances among all anecdotes divided by the number of anecdotes. However, whether a customer will face stockout or not is a new and independent draw from the actual stockout probability. The firm sets the capacity before period 1 and Huang and Liu consider two settings: (i) capacity commitment, where the firm commits to the capacity level; (ii) dynamic capacity management, where the firm can adjust her capacity level in each period. Huang and Liu find that within the simplest form of anecdotal reasoning (i.e., each customer obtains only one anecdote), strategic capacity rationing is sub-optimal for both settings. This is because anecdotal reasoning leads customer to hold different estimates of the stockout probability, which weakens the advantage of capacity rationing 
in optimally influencing customers' strategic purchase behavior.

Huang and Liu focus on customer anecdotal reasoning in estimating the future product availability. In practice, customers may also use anecdotes to estimate the probability of future sales. Huang et al. [83] investigate the impact of anecdotal reasoning on a firm's posterior price-matching strategy, i.e., reimbursing the price difference to a customer who purchases a product before the firm marks it down. Specifically, they assume that customers estimate the probability of future sales based on earlier customers' experiences of the regular and sales prices. They find that a firm should adopt posterior price-matching in cases where she should not in the absence of customer anecdotal reasoning. This is because posterior price-matching and markdown with a positive probability create price obfuscation and can fool some customers into paying a higher price upfront because they falsely expect to be compensated later.

Another setting where customers are prone to anecdotal reasoning is opaque selling, a selling strategy in which a firm mixes different types of a product to sell as an opaque product. The traditional literature on opaque selling (see, e.g., [92, 93, 94, 95, 96, 97, 98, 99, 100]) assumes that customers anticipate the product mix (the probability of ending up with each type of product) with full rationality. This may not hold in practice. For example, "decoder" websites (e.g., BiddingFor-Travel.yuku.com, BetterBidding.com, BidOnTravel.com) use feedback/experiences from previous purchasers to help customers learn more about the sellers' product offering strategies under opaque selling.

Huang and $\mathrm{Yu}$ [84] examine the impact of customer anecdotal reasoning on a firm's opaque selling strategy. To this end, they consider a monopolist firm selling a product of two different "versions" (i.e., with different values) to generations of homogeneous customers with a deterministic size. Before the arrival of the first generation, the firm chooses among: (i) selling the two versions separately (i.e., as transparent products); (ii) mixing the two versions and selling them as an opaque product; (iii) selling both transparent and opaque products at the same time. Customers observe the price(s) but not the product mix, and they anticipate to receive the same product as the product from an anecdote. 
However, her own product offered by the firm is an independent realization from the firm's actual product offering strategy. This model eliminates all possible conditions that can support opaque selling in the fully rational benchmark. However, Huang and Yu show that anecdotal reasoning alone can make opaque selling optimal. The key insight is that anecdotal reasoning leads customers to hold different estimates about the value of the opaque product: some customers overestimate the probability to receive the high-value product and thus are willing to pay a high price, whereas the others underestimate the probability and are willing to pay a low price. By optimizing over the product offering, the firm may be able to take advantage of the overestimating customers without turning away too many underestimating customers. This allows her to obtain more profits than selling only transparent products. Considering market competition, Huang and Yu find that opaque selling may soften price competition and increase the industry profits even in the absence of customers' valuation heterogeneity.

We would like to note that Huang and Yu adopt a parsimonious model to show that opaque selling can be supported by anecdotal reasoning alone. In fact, opaque selling has been adopted in more complex settings and thus customers may demonstrate other types of bounded rationality. For example, opaque selling has been applied as a clearance strategy to strategic customers (see [101] for examples), and the existing literature has compared the performance of opaque selling and last-minute selling (selling transparent products instead of opaque products at a discount in the sales season) in horizontally-differentiated [101] and vertically-differentiated [100] markets. They find that opaque selling may outperform last-minute selling by increasing the regular price: customers are willing to pay more in the regular selling season because they are not guaranteed to receive the preferred type of product if they buy the opaque product in the sales season. According to the discussions of Su [80] and Zhao and Stecke [85. (to be reviewed in Section 3.5), customers in this setting are prone to loss aversion and inertia. Therefore, future research may investigate the impact of these types of bounded rationality on a firm's product mixing strategy in opaque s30 selling and its profitability compared to last-minute selling. This investigation 
becomes particularly relevant as one considers the complex impact of loss aversion and inertia on customers' purchase decisions. For example, loss aversion may decrease the appeal of opaque selling because customers incur a profit loss if they do not receive the preferred type of product. Knowing this, they are willing to pay a higher price in the regular selling season, so opaque selling can become more attractive.

In our view, the anecdotal reasoning framework can be applied to more OM settings to derive new insights for academics and practitioners. For example, customer anecdotal reasoning on product availability may impact a retailer's dynamic pricing and inventory decisions, as well as the supply chain contracts. In essence, anecdotal reasoning is a heuristic for customers to estimate uncertainties to which they have scarce previous exposures. This trait makes anecdotal reasoning a strong modeling tool in many OM settings. First, uncertainties about product availability, service delivery, and demand usually play a key role in OM. Second, customers are typically much less informed about these uncertainties than firms. Third, the development of information technology allows customers to acquire word-of-mouth information about these uncertainties. Meanwhile, it provides firms the opportunity to manage word-of-mouth by, e.g., inviting for expert reviews and rewarding customers to post reviews. Therefore, incorporating customer anecdotal reasoning in OM can offer a fertile avenue for future research with strong managerial relevance.

\subsection{Cognitive Hierarchy}

Whereas the previous modeling tools capture a decision-maker's limitation in understanding her benefits and costs from each option, cognitive hierarchy models one's reasoning limitation in anticipating the other decision-makers' strategic responses. This feature may have important implications for many OM settings. In SOM, for example, some customers may not anticipate other customers' join-or-balk decisions fully rationally, especially in invisible queues in which customers may have no interaction with each other when making decisions. Similarly, in RM a customer may not be able to rationally infer whether 
the other customers decide to buy now or wait for future sales.

Despite its importance, cognitive hierarchy has not been incorporated into OM settings, with the only exception of Cui and Zhang [86. They consider a supply chain consisting of a single supplier and many retailers, each of whom faces a deterministic demand that aggregately exceeds the supplier's capacity. The supplier adopts proportional allocation, and the retailers order at the maximum allowed amount if they can infer each other's decision rationally. To capture their bounded rationality, Cui and Zhang assume that retailers exhibit Poisson cognitive hierarchy (see Section 2.3). Cui and Zhang find that the retailers' ordering decisions differ significantly from the fully rational benchmark. In particular, unsophisticated retailers order less than the maximum allowed amount, and they order even less as the number of retailers increases or the supplier's production capacity expands. In addition, the retailers' profits exhibit an inverted U-shaped relationship to their level of sophistication, i.e., benefit with some levels of sophistication but become worse off with too much. Then Cui and Zhang structurally estimate the model parameters and calibrate the level of sophistication using data from an experiment, and they show that the estimated model fits the data reasonably well.

\subsection{Hyperbolic Discounting}

The concept of hyperbolic discounting, as introduced in Section 2.4. provides a tractable method to model customers' procrastination behavior. Specifically, since their discount rate is decreasing over time, customers may delay a purchase to the future, although it is optimal to buy now. In this section, we will review several papers that incorporate this procrastination behavior into SOM and RM.

In many service systems (e.g., flu shot clinic, exercise facility, barber shop, and car wash), a customer needs to undergo an unpleasant service that would generate future benefits (e.g., exercise facility, flu shot clinic, and car wash). The psychology and economics literature (e.g., [102, 46, 103]) has shown that 
should. To exploit customers' procrastination, many service systems charge customers a subscription fee instead or in addition to the fee per use (the usage fee, hereafter). However, the traditional queueing economics literature shows that the usage fee alone can achieve revenue maximization (p. 45-51 of [89]).

To capture customers' lack of self-control and explain the application of subscription fee, Plambeck and Wang [75] incorporate the quasi-hyperbolic discounting in customers' preferences. They characterize customers' decisions of subscribing for service and if they subscribe, whether to join or balk the service system when the need for service occurs. In addition, the customers may be naïve in the sense of overestimating her self-control when deciding to subscribe or not, or sophisticated in the sense of estimating her self-control correctly. Plambeck and Wang find that the lack of self-control lowers the revenue- and welfare-maximizing usage fees. Charging for subscription, in addition to or instead of per use, increases revenue, especially when subscribers are naïve. If the service provider chooses between charging for subscription only or usage fee only, then subscription is optimal for revenue maximization, whereas usagebased pricing is optimal for welfare maximization.

In another paper, $\mathrm{Su}$ [80] studies the implications of customers' procrastination in RM. To this end, he revises the strategic customers' decision framework by assuming that they buy a product now instead of waiting for future sales if the expected utility of buying exceeds the expected utility of waiting by a positive constant. This constant represents the incremental utility premium necessary to trigger a purchase and thus captures the depth of customer inertia. This purchase inertia may arise from different types of bounded rationality (i.e., hyperbolic discounting, loss aversion, and probability weighting), and we refer interested readers to Section 5 of 80 for a detailed discussion.

Using this customer inertia framework, Su investigates a monopolistic firm's dynamic pricing decision on a single type of product considering demand uncertainty, customers' valuation uncertainty, and fixed capacity. A portion of the ${ }_{520}$ customers arrive at the market in period 1 while the rest arrive in period 2. Moreover, period- 1 customers consist of both rational and inertial customers, 
and the portion of inertial customers represents the breadth of inertia. The seller sets the period-1 price without observing the realized demand and customers make the purchase decision without knowing their product valuations. In period 2 , however, the seller sets the price and customers make the purchase decision after both uncertainties are resolved. Su characterizes the optimal pricing strategies across the two periods and finds that the seller's profit is hurt by the depth of inertia because it leads the firm to price lower to stimulate purchases. In contrast, the breadth of inertia may benefit the seller: a larger portion of inertial customers suggests a higher demand in period 2, which in turn makes stockout more likely to happen and thus rational customers are more willing to buy in period 1 .

\subsection{Reference Dependence and Loss Aversion}

It has been well-documented (see [104, 105] for surveys) that individual preferences are reference dependent. In the dynamic pricing setting, this reference dependence can be particularly significant: "as customers revisit the firm, they develop price expectations, or reference prices, which become the benchmark against which current prices are compared." 76] To investigate a monopolistic firm's dynamic pricing strategy when facing reference-dependent customers, Popescu and Wu [6] consider a firm's infinite-horizon pricing problem facing a general nonlinear demand ${ }^{1}$ which depends on a reference price determined by the historical prices. In this setting, loss aversion suggests that customers are more responsive to surcharges than discounts, while loss seeking suggests the opposite. Popescu and Wu characterize the optimal pricing strategy and find that the optimal policy cycles if customers are loss seeking, and there is a range of steady states if customers are loss averse. Moreover, the price trajectory in the loss aversion setting is either increasing or decreasing, and using the optimal fixed price is near-optimal. Nasiry and Popescu [77] extend the model by

\footnotetext{
${ }^{1}$ Kopalle et al. [106 and Fibich et al. [107 show monotonicity and convergence of the optimal price paths under a piecewise linear demand model.
} 
considering peak-end anchoring, i.e., the reference price is a weighted average of the lowest and most recent prices.

Subsequent research applies the model of 76 to inventory management. Chen et al. [78 consider a periodic-review stochastic inventory model where a firm makes the pricing and inventory decisions to customers who exhibit the reference price effect. They characterize the optimal inventory policy as a reference-price-dependent, base-stock policy and show that as customers become more reference dependent, the optimal price decreases whereas the optimal base-stock level may increase or decrease depending on whether there is a perceived loss or perceived gain.

Baron et al. 79] extend Chen et al. by incorporating customers' reference dependence on both price and fill rate. Specifically, they consider a newsvendor who sells a perishable asset over repeated periods to loss-averse customers with stochastic reference points that represent their beliefs about the price and product availability. In each period, given the distribution of the reference points, customers choose the purchase plan to maximize the total utility (i.e., the outcome-based utility and the gain-loss utility) before visiting the store, and then commit to the plan after learning the realized price and availability in the store. Fully aware of customers' purchase plan, the newsvendor maximizes her expected long-run average profit by choosing the ordering quantity before observing the demand and the contingent price (i.e., a full price or a sale price) based on the demand realization. In equilibrium, the customers' reference points distribution is consistent with the newsvendor's pricing and ordering decisions.

Based on this newsvendor model, Baron et al. characterize customers' purchase decision and the newsvendor's optimal inventory and contingent pricing policies. They find that the customers' loss aversion leads to two countervail575 ing effects of running sales: (i) the comparison effect: higher sales frequency increases the weight of sale prices in the loss-averse customers' reference distribution, making customers used to the sale price and less likely to purchase at the full price; (ii) the attachment effect: higher sales frequency increases customers' psychological attachment to the habit of purchasing and thus makes 

product when there are no sales. Because of these effects, customers may be willing to pay a full price higher than their valuation and the firm offers sales less frequently than the fully rational benchmark. In addition, loss aversion affects the newsvendor's optimal operational policies that are in stark contrast to those the initial ordering quantity and decreases in the procurement cost; the optimal sales frequency increases in the procurement cost; demand variability may benefit the newsvendor.

All the papers above assume that customers cannot delay their purchases obtained in classic newsvendor models, e.g., the optimal full price increases in o a later time. In practice, they may do so based on strategic considerations (e.g., waiting for sales). Therefore, it would be interesting for future research to examine how loss aversion influences strategic customers' purchase decisions and a firm's pricing and inventory decisions.

Apart from dynamic pricing, customers' loss aversion may also play an important role in other OM settings where a salient reference point exists. For example, in deciding to adopt capacity rationing or not, a firm may take into account the customers' aversion to stockout. Liu and Shum [82] analyze the impact of this loss aversion on a firm's capacity rationing and pricing decisions. They find that when strategic customers are averse to disappointment, a firm may be able to increase profits with an appropriate level of rationing. Moreover,

them more willing to pay the full price to avoid the pain of not obtaining the customers' loss aversion may also impact a firm's advance selling strategy, i.e., offering pre-orders at a discount. The RM literature has shown that advance selling benefits the firm by allowing her to learn demand information and get business from customers who would otherwise not buy because their valuations, which are realized after the product release, are too low (see [108] for a literature review). Zhao and Stecke [85] extend this literature by assuming that part of the customers are loss averse: after placing a pre-order, they incur a payoff loss when the product valuation turns out to be lower than the price. Therefore, loss aversion reduces the appeal of advance selling. Zhao and Stecke characterize the firm's optimal selling strategy and show that as customers become more 
loss-averse, the firm offers advance selling for a narrower range of parameter values.

In our view, the advance selling setting is particularly relevant in studying the role of customer bounded rationality and future research may focus on the setting.

Despite the lack of a unified model, researchers have incorporated trust and trustworthiness in SCM using setting-specific models. In particular, Özer et al. [87. consider the role of trust and trustworthiness in a manufacturer's decision of Özer et al. 87] assume that: (i) the supplier follows a non-Bayesian updating rule where her belief of demand strictly increases in the shared demand forecast information (i.e., she trusts the retailer); (ii) the manufacturer suffers from disutility in proportional to the magnitude of misreporting the demand forecast ${ }_{640}$ (i.e., she is trustworthy). Özer et al. find that this trust-embedded model 
supports cooperation in information sharing between the manufacturer and the supplier. This is consistent with their experimental studies yet is missing from the traditional literature that does not consider trust and trustworthiness. In a similar vein, Özer et al. 88, show that trust and trustworthiness can also 645 support a supplier's information sharing to a retailer about the retailer service level, e.g., shelf space allocation, shelf design, and product promotion.

Although the existing literature focuses on information sharing within supply chains, we believe that trust and trustworthiness can have a much broader impact on other market participants. The customers, for example, are usually less informed about the market than the firms. This makes trust and trustworthiness an interesting research topic in many OM settings. In diagnosis-service systems, it may be difficult for ordinary customers to evaluate the truthfulness of a diagnosis outcome reported by the service provider (e.g., a car maintenance company or a dentist). If they trust the diagnosis to some extent, how should the service provider price the diagnosis and the repair service? Another interesting OM setting is a firm's dynamic pricing strategy considering customers' strategic behavior. Apart from the firm's own report, the customers may have scarce information about the future availability of the product. If they trust the firm's report to some extent, how should the firm adjust her capacity and pricing strategies in response?

\section{Conclusions and Future Research Directions}

As shown in the previous section, the contributions of modeling decisionmakers' bounded rationality in OM are both positive and normative. It offers testable explanations for human decision-makers' behavioral anomalies in OM settings (e.g., the pull-to-center effect and the bullwhip effect [70]), and also provides behavioral groundings and policy recommendations for firms' operations and marketing strategies (e.g., opaque selling [84] and advance selling [85]).

Since the OM literature on bounded rationality is still at its nascence, many interesting and important topics have not yet been fully explored. Perhaps the 

especially in SOM and RM. Future empirical studies may test these models by: (i) quantifying the level of customer bounded rationality (e.g., the variance of the error term in the logit choice model and the size of anecdotes in the anecdotal reasoning framework) in the corresponding OM setting; (ii) investigating how Several interesting conjectures include: are customers more boundedly rational when the OM setting is more complicated (e.g., more uncertainty in the demand distribution, an invisible queue instead of a visible queue)? Are customers more boundedly rational when the payoff loss due to a bad purchase is higher rationality in $\mathrm{OM}$, and future research may derive new insights even within the established settings. We have articulated several specific extensions after the corresponding reviewed papers in Section 3 , and below we provide the general research directions. chain participants. In practice, however, customers may exhibit bounded rationality to a larger extent. This is because customers are usually less informed about the market, they interact with the market less often, and they are not aided by dedicated decision-making systems. Based on these considerations, 
insights to SCM.

In SOM and RM, researchers have focused exclusively on the settings in which all customers exhibit the same level of bounded rationality. This may not hold in practice. For example, some customers may visit a restaurant as

\section{References}

[1] H. A. Simon, A behavioral model of rational choice, The Quarterly Journal of Economics (1955) 99-118.

[2] H. A. Simon, Models of man: Social and rational, John Wiley \& Sons, 720

[3] R. D. Luce, Individual choice behavior: A theoretical analysis, John Wiley \& Sons, 1959.

[4] R. D. McKelvey, T. R. Palfrey, Quantal response equilibria for Normal form games, Games and Economic Behavior 10 (1) (1995) 6-38.

725 long as the food quality is high (i.e., they totally ignore the waiting cost and thus are fully boundedly rational), some may anticipate a line consisting of fully boundedly rational customers, while some others may check websites and mobile apps to learn the waiting cost in real time. This heterogeneity is particularly setient in many OM settings (e.g., invisible queues and dynamic pricing and rect contact with other customers. Therefore, it would be interesting to expand the application of cognitive hierarchy in SOM and RM and derive new insights from customer heterogeneity in their levels of rationality. Moreover, we believe that anecdotal reasoning also has great future research opportunities in many SOM and RM settings (see Section 3.2 for a detailed discussion).
] H.-C. Chen, J. W. Friedman, J.-F. Thisse, Boundedly rational Nash equilibrium: A probabilistic choice approach, Games and Economic Behavior 18 (1) (1997) 32-54. 
[6] A. Rubinstein, Modeling bounded rationality, MIT press, 1998.

[7] R. Spiegler, Bounded rationality and industrial organization, Oxford University Press, 2011.

[8] D. O. Stahl, P. W. Wilson, Experimental evidence on players' models of other players, Journal of Economic Behavior \& Organization 25 (3) (1994) 309-327.

[9] R. Nagel, Unraveling in guessing games: An experimental study, The American Economic Review 85 (5) (1995) 1313-1326.

[10] L. L. Thurstone, A law of comparative judgment, Psychological Review 34 (4) (1927) 273.

[11] S. Pinker, The better angels of our nature: The decline of violence in history and its causes, Penguin UK, 2011.

[12] D. J. Murray, A perspective for viewing the history of psychophysics, Behavioral and Brain Sciences 16 (1) (1993) 115- 137.

[13] L. L. Thurstone, Psychophysical analysis, The American Journal of Psychology 38 (3) (1927) 368-389.

[14] D. McFadden, Conditional logit analysis of qualitative choice behavior, https://elsa.berkeley.edu/reprints/mcfadden/zarembka.pdf, Accessed on 17 August 2016 (1973).

[15] S. P. Anderson, A. De Palma, J. F. Thisse, Discrete choice theory of product differentiation, MIT press, 1992.

[16] P. Bajari, A. Hortacsu, et al., Auction models when bidders make small mistakes: Consequences for theory and estimation, Working Paper, Stanford University, Stanford, CA.

[17] P. Bajari, A. Hortacsu, Are structural estimates of auction models reasonable? Evidence from experimental data, Journal of Political Economy 113 (4) (2005) 703-741. 
[18] T. N. Cason, S. S. Reynolds, Bounded rationality in laboratory bargaining with asymmetric information, Economic Theory 25 (3) (2005) 553-574.

[19] S. Basov, Monopolistic screening with boundedly rational consumers, Economic Record 85 (s1) (2009) S29-S34.

[20] M. J. Osborne, A. Rubinstein, Games with procedurally rational players,

[21] A. Tversky, D. Kahneman, Belief in the law of small numbers., Psychological Bulletin 76 (2) (1971) 105.

[22] D. Kahneman, A. Tversky, Subjective probability: A judgment of representativeness, Cognitive Psychology 3 (3) (1972) 430-454.

[23] R. Spiegler, The market for quacks, The Review of Economic Studies 73 (4) (2006) 1113-1131.

[24] N. Szech, Becoming a bad doctor, Journal of Economic Behavior \& Organization 80 (1) (2011) 244-257.

[25] R. Spiegler, Competition over agents with boundedly rational expectations, Theoretical Economics 1 (2) (2006) 207-231.

[26] C. Camerer, Behavioral game theory: Experiments in strategic interaction, Princeton University Press, 2003.

[27] C. F. Camerer, T.-H. Ho, J.-K. Chong, A cognitive hierarchy model of games, The Quarterly Journal of Economics (2004) 861-898.

775

[28] V. P. Crawford, N. Iriberri, Level-k auctions: Can a nonequilibrium model of strategic thinking explain the winner's curse and overbidding in privatevalue auctions?, Econometrica 75 (6) (2007) 1721-1770.

[29] S. Choi, A cognitive hierarchy model of learning in networks, Review of Economic Design 16 (2-3) (2012) 215-250. 
[41] U. Benzion, A. Rapoport, J. Yagil, Discount rates inferred from decisions: An experimental study, Management Science 35 (3) (1989) 270-284.

[42] L. Green, A. F. Fry, J. Myerson, Discounting of delayed rewards: A lifespan comparison, Psychological Science 5 (1) (1994) 33-36. 
[43] G. B. Chapman, A. S. Elstein, Valuing the future temporal discounting of health and money, Medical Decision Making 15 (4) (1995) 373-386.

[44] K. N. Kirby, Bidding on the future: evidence against normative discounting of delayed rewards., Journal of Experimental Psychology: General 126 (1) (1997) 54.

[45] G. B. Chapman, E. J. Coups, Time preferences and preventive health behavior acceptance of the influenza vaccine, Medical Decision Making 19 (3) (1999) 307-314.

[46] S. Frederick, G. Loewenstein, T. O'donoghue, Time discounting and time preference: A critical review, Journal of Economic Literature 40 (2) (2002) $351-401$.

[47] G. Ainslie, Specious reward: a behavioral theory of impulsiveness and impulse control., Psychological Bulletin 82 (4) (1975) 463.

[48] R. J. Herrnstein, Self-control as response strength, Quantification of Steady-State Operant Behavior (1981) 3-20.

[49] J. E. Mazur, An adjusting procedure for studying delayed reinforcement, The Effect of Delay and Intervening Events on Reinforcement Value, Chapter 3 (1987) 55-73.

[50] G. Loewenstein, D. Prelec, Anomalies in intertemporal choice: Evidence and an interpretation, The Quarterly Journal of Economics (1992) 573597.

[51] D. Laibson, Golden eggs and hyperbolic discounting, The Quarterly Journal of Economics (1997) 443-477.

[52] J. Gruber, B. Köszegi, Is addiction rational? theory and evidence, The Quarterly Journal of Economics 116 (4) (2001) 1261-1303.

[53] S. DellaVigna, U. Malmendier, Contract design and self-control: Theory and evidence, The Quarterly Journal of Economics (2004) 353-402. 
[54] D. Kahneman, A. Tversky, Prospect theory: An analysis of decision under risk, Econometrica. (1979) 263-291.

[55] R. Thaler, Toward a positive theory of consumer choice, Journal of Economic Behavior \& Organization 1 (1) (1980) 39-60.

[56] D. Kahneman, J. L. Knetsch, R. H. Thaler, Experimental tests of the endowment effect and the coase theorem, Journal of Political Economy (1990) 1325-1348.

[57] B. Koszegi, P. Heidhues, The impact of consumer loss aversion on pricing, Working Paper, University of California, Berkeley.

[58] P. Heidhues, B. Kőszegi, Competition and price variation when consumers are loss averse, The American Economic Review 98 (4) (2008) 1245-1268.

[59] P. Heidhues, B. Kőszegi, Regular prices and sales, Theoretical Economics 9 (1) (2014) 217-251.

[60] B. Kőszegi, M. Rabin, A model of reference-dependent preferences, The Quarterly Journal of Economics (2006) 1133-1165.

[61] C. Camerer, L. Babcock, G. Loewenstein, R. Thaler, Labor supply of new york city cabdrivers: One day at a time, The Quarterly Journal of Economics (1997) 407-441.

[62] H. Shefrin, M. Statman, The disposition to sell winners too early and ride losers too long: Theory and evidence, The Journal of Finance 40 (3) (1985) 777-790.

[63] M. Weber, C. F. Camerer, The disposition effect in securities trading: An experimental analysis, Journal of Economic Behavior \& Organization 33 (2) (1998) 167-184.

[64] D. Genesove, C. Mayer, Loss aversion and seller behavior: Evidence from the housing market, Quarterly Journal of Economics (2001) 1233-1260. 
[65] S. Benartzi, R. H. Thaler, Myopic loss aversion and the equity premium puzzle, The Quarterly Journal of Economics 110 (1) (1995) 73-92.

[66] D. S. Putler, Incorporating reference price effects into a theory of consumer choice, Marketing Science 11 (3) (1992) 287-309.

[67] B. G. Hardie, E. J. Johnson, P. S. Fader, Modeling loss aversion and reference dependence effects on brand choice, Marketing Science 12 (4) (1993) 378-394.

[68] J. Shea, Union contracts and the life-cycle/permanent-income hypothesis, The American Economic Review (1995) 186-200.

[69] D. Bowman, D. Minehart, M. Rabin, Loss aversion in a consumptionsavings model, Journal of Economic Behavior \& Organization 38 (2) (1999) 155-178.

[70] X. Su, Bounded rationality in newsvendor models, Manufacturing \& Service Operations Management 10 (4) (2008) 566-589.

[71] T. Huang, G. Allon, A. Bassamboo, Bounded rationality in service systems, Manufacturing \& Service Operations Management 15 (2) (2013) 263-279.

[72] X. Li, P. Guo, Z. Lian, Quality-speed competition in customer-intensive services with boundedly rational customers, Production \& Operations Management 25 (11) (2016) 1885-1901.

[73] T. Huang, Y.-J. Chen, Service systems with experience-based anecdotal reasoning customers, Production \& Operations Management 24 (5) (2015) $778-790$.

[74] H. Ren, T. Huang, K. Arifoglu, Managing service systems with unknown quality and customer anecdotal reasoning, Working Paper, University Colege London. 
[75] E. L. Plambeck, Q. Wang, Implications of hyperbolic discounting for optimal pricing and scheduling of unpleasant services that generate future benefits, Management Science 59 (8) (2013) 1927-1946.

[76] I. Popescu, Y. Wu, Dynamic pricing strategies with reference effects, Operations Research 55 (3) (2007) 413-429.

[77] J. Nasiry, I. Popescu, Dynamic pricing with loss-averse consumers and peak-end anchoring, Operations Research 59 (6) (2011) 1361-1368.

[78] X. Chen, P. Hu, S. Shum, Y. Zhang, Dynamic stochastic inventory management with reference price effects, Operations Research 64 (6) (2016) $1529-1536$.

[79] O. Baron, M. Hu, S. Najafi-Asadolahi, Q. Qian, Newsvendor selling to loss-averse consumers with stochastic reference points, Manufacturing \& Service Operations Management 17 (4) (2015) 456-469.

[80] X. Su, A model of consumer inertia with applications to dynamic pricing, Production \& Operations Management 18 (4) (2009) 365-380.

[81] T. Huang, Q. Liu, Strategic capacity management when customers have boundedly rational expectations, Production \& Operations Management 24 (12) (2015) 1852-1869.

[82] Q. Liu, S. Shum, Pricing and capacity rationing with customer disappointment aversion, Production \& Operations Management 22 (5) (2013) 1269-1286.

[83] T. Huang, Z. Yin, Y.-J. Chen, Managing posterior price matching: The role of customer boundedly rational expectations, Manufacturing \& Service Operations Management 19 (3) (2017) 385-402.

[84] T. Huang, Y. Yu, Sell probabilistic goods? a behavioral explanation for opaque selling, Marketing Science 33 (5) (2014) 743-759. 
[85] X. Zhao, K. E. Stecke, Pre-orders for new to-be-released products considering consumer loss aversion, Production \& Operations Management 19 (2) (2010) 198-215.

[86] T. H. Cui, Y. Zhang, Cognitive hierarchy in capacity allocation games, Available at SSRN 2676402.

[87] Ö. Özer, Y. Zheng, K.-Y. Chen, Trust in forecast information sharing, Management Science 57 (6) (2011) 1111-1137.

[88] Ö. Özer, U. Subramanian, Y. Wang, Information sharing, advice provision or delegation: What leads to higher trust and trustworthiness?, Management Science, Article in Advance.

[89] R. Hassin, M. Haviv, To queue or not to queue: Equilibrium behavior in queueing systems, Vol. 59, Springer Science \& Business Media, 2003.

[90] G. R. Bitran, J.-C. Ferrer, P. Rocha e Oliveira, Om forum-managing customer experiences: Perspectives on the temporal aspects of service encounters, Manufacturing \& Service Operations Management 10 (1) (2008) $61-83$.

[91] Z.-J. M. Shen, X. Su, Customer behavior modeling in revenue management and auctions: A review and new research opportunities, Production \& Operations Management 16 (6) (2007) 713-728.

[92] Y. Jiang, Price discrimination with opaque products, Journal of Revenue and Pricing Management 6 (2) (2007) 118-134.

[93] S. Fay, J. Xie, Probabilistic goods: A creative way of selling products and services, Marketing Science 27 (4) (2008) 674-690.

[94] S. Fay, Selling an opaque product through an intermediary: The case of disguising one's product, Journal of Retailing 84 (1) (2008) 59-75.

[95] D. Shapiro, X. Shi, Market segmentation: The role of opaque travel agencies, J. Econ. Manage. Strat. 17 (4) (2008) 803-837. 
[96] S. Fay, J. Xie, Timing of product allocation: using probabilistic selling to enhance inventory management, Management Science 61 (2) (2014) $474-484$.

[97] S. Fay, J. Xie, C. Feng, The effect of probabilistic selling on the optimal product mix, Journal of Retailing 91 (3) (2015) 451-467.

[98] C. K. Anderson, X. Xie, Pricing and market segmentation using opaque selling mechanisms, European Journal of Operations Research 233 (1) (2014) 263-272.

[99] D. H. Rice, S. A. Fay, J. Xie, Probabilistic selling vs. markdown selling: Price discrimination and management of demand uncertainty in retailing, International Journal of Research in Marketing 31 (2) (2014) 147-155.

[100] Z. Zhang, K. Joseph, R. Subramaniam, Probabilistic selling in qualitydifferentiated markets, Management Science 61 (8) (2014) 1959-1977.

[101] K. Jerath, S. Netessine, S. K. Veeraraghavan, Revenue management with strategic customers: Last-minute selling and opaque selling, Management Science 56 (3) (2010) 430-448.

[102] G. Ainslie, Picoeconomics: The strategic interaction of successive motivational states within the person, Cambridge University Press.

[103] S. D. Vigna, U. Malmendier, Paying not to go to the gym, The American Economic Review 96 (3) (2006) 694-719.

[104] H. Arslan, S. Kachani, Dynamic pricing under consumer reference-price effects, Wiley Encyclopedia of Operations Research and Management Science.

960 [105] Ö. Özer, R. Phillips, Behavioral issues in pricing management, The Oxford Handbook of Pricing Management, Chap. 20 (Oxford University Press, Oxford, UK) (2012) 415-461. 
[106] P. K. Kopalle, A. G. Rao, J. L. Assuncao, Asymmetric reference price effects and dynamic pricing policies, Marketing Science 15 (1) (1996) 6085.

[107] G. Fibich, A. Gavious, O. Lowengart, Explicit solutions of optimization models and differential games with nonsmooth (asymmetric) referenceprice effects, Operations Research 51 (5) (2003) 721-734.

[108] A. Prasad, K. E. Stecke, X. Zhao, Advance selling by a newsvendor retailer, Production \& Operations Management 20 (1) (2011) 129-142.

[109] K. J. Arrow, Gifts and exchanges, Philosophy \& Public Affairs (1972) $343-362$.

[110] S. Knack, P. Keefer, Does social capital have an economic payoff? a crosscountry investigation, The Quarterly Journal of Economics 112 (4) (1997) $1251-1288$.

[111] E. Fehr, J. A. List, The hidden costs and returns of incentives? trust and trustworthiness among ceos, Journal of the European Economic Association 2 (5) (2004) 743-771.

[112] D. S. Karlan, Using experimental economics to measure social capital and predict financial decisions, American Economic Review 95 (5) (2005) 1688-1699. 